\title{
A Dynamic General Equilibrium Framework of Investment with Financing Constraint
}

\author{
DANYANG XIE and CHI-WA YUEN*
}

In this paper, we provide a dynamic general equilibrium framework with an explicit investment-financing constraint. The constraint is intended as a reduced form to capture the balance sheet effects that have been widely regarded as an important determinant of financial crises. We derive a link between the value of a firm and social welfare. Using this link, we show the somewhat surprising possibility that the value of a firm can be greater with the constraint. Our model also sheds light on how the effects of productivity shocks and investors' misperception of productivity shocks may be amplified by the financing constraint. [JEL C61, D92]

\begin{abstract}
A $t$ the very beginning of the Asian financial crisis, most people took it to be yet another currency crisis and many saw it as the second generation (selffulfilling) type à la Obstfeld (1996) rather than a first generation (fundamental) type à la Krugman (1979). As the crisis unfolded, however, it became obvious that, unlike exchange rate crises, the Asian financial crisis was more related to banking and financial problems in financing business investment. Since then, quite a few theories (so-called "third generation" models) have been proposed to explain its sources-moral hazard or guaranteed bailouts (Krugman, 1998), financial fragility (Chang and Velasco, 2000), and balance sheet effects (Krugman, 1999). ${ }^{1}$
\end{abstract}

\footnotetext{
${ }^{*}$ Danyang Xie is a Senior Economist at the IMF Institute and Chi-Wa Yuen is a visiting professor at Peking University and Wuhan University (on leave from the University of Hong Kong). We thank the Hong Kong Research Grants Councils for financial support. We appreciate comments from Andrew Feltenstein, Eduardo Ley, Rodney Ramcharan, Reza Vaez-Zadeh, two anonymous referees, and the editor, Robert Flood.

${ }^{1}$ See Schneider and Tornell (2000) for an attempt to synthesize some of these effects.
} 
As Krugman (2002) concludes, balance sheet effects are now believed to be the most crucial element behind the Asian financial crisis. In particular, if firms are highly leveraged with debt denominated in foreign currency, then anything that triggers a massive capital outflow will result in a depreciation of the domestic currency and thus an increase in the firms' debt burden. As a consequence, net worth of the firms will be reduced, limiting their ability to borrow to finance new investment. The resulting investment and output collapse will validate the capital flight and make the crisis self-fulfilling.

Despite its general acceptance by the profession as an important determinant of financial crises, the balance sheet effect has been studied mostly in models with complicated banking structure and multiple types of agents. For studies of firms' balance sheet effects on the business cycle, see Carlstrom and Fuerst (1997) and Bernanke, Gertler, and Gilchrist (1999). For a growth analysis that incorporates banks' balance sheet effects, see Chakraborty and Ray (2001). The balance sheet effect has also been included in the study of the bank capital channel of monetary policy (see Van den Heuvel, 2001; Kashyap and Stein, 1995; and Chami and Cosimano, 2001). A related set of papers that emphasize the role of durable assets as collateral include those of Kiyotaki and Moore (1997) and Chen (2001).

In this paper, we present a dynamic general equilibrium framework with an infinitely long-lived representative agent. We impose an explicit investmentfinancing constraint that is intended as a reduced form to capture the balance sheet effects. At the expense of microfoundations, our approach has the advantage of simplicity. We think of our contribution as similar to that of the moneyin-utility-function (MIUF). The MIUF complements the cash-in-advance (CIA) and the overlapping-generation (OLG) models of money with more microfoundation. The lasting influence of MIUF is clearly seen in its wide adoption in the recent open economy macroeconomics literature (see Obstfeld and Rogoff, 1996). It is certainly our hope to see a future adaptation of our investmentfinancing constraint to real business cycle models, but as a first step, we focus on a continuous-time and deterministic setting.

In this setup, we derive a link between the value of a firm and social welfare. We find that the value of a firm can be greater with the constraint. Our model also sheds light on how the effects of productivity shocks and investors' misperception of productivity shocks may be amplified by the financing constraint. We also discuss shocks such as accounting scandals that worsen the information asymmetry and shocks that enhance transparency, such as improved accounting standards and disclosure rules.

\section{The Model}

Consider an infinite horizon economy where capital is the only factor of production. The representative household is endowed with some initial stock of capital, $k_{0}$. Using this capital stock, the household sets up a representative firm to produce output and to invest in new capital. The firm's output net of investment will be distributed back to the household to support its consumption. 


\section{The Firm's Value Maximization Problem}

At any time $t$, the firm uses capital, $k_{t}$, to produce output, $f\left(k_{t}\right)$, and invests an amount, $\dot{k}+\delta k$ (where $\delta$ is the depreciation rate). The firm's problem is to choose $\dot{k}$ to maximize the present value of output net of investment, i.e.,

$$
V^{o}\left(k_{0}\right)=\max \int_{0}^{\infty} e^{-\int_{0}^{t} r_{s} d s}[f(k)-\delta k-z] d t
$$

subject to: $\dot{k}=z$

$$
k_{0} \text { given, }
$$

where $z$ is net investment. The superscript $o$ stands for original, emphasizing the situation without an investment-financing constraint. Implicitly, we are assuming that the firm borrows funds from banks at a competitive interest rate $r_{t}$ to finance its investment. A more explicit discussion about the role of the banking sector in this model economy is contained in Appendix I.

The first-order conditions of this problem imply the familiar interest rate expression as follows:

$$
r_{t}=f^{\prime}\left(k_{t}\right)-\delta
$$

\section{The Consumer's Utility Maximization Problem}

The consumer's problem is simply to choose consumption, $\left\{c_{t}\right\}_{0}^{\infty}$, to maximize utility subject to the budget constraint that the present value of her consumption cannot exceed the value of the firm she owns, i.e.,

$$
U^{o}\left(k_{0}\right)=\max \int_{0}^{\infty} e^{-\rho t}\left(\frac{c^{1-\sigma}-1}{1-\sigma}\right) d t
$$

subject to: $\int_{0}^{\infty} e^{-\int_{0}^{t} r_{s} d s} c d t \leq V^{o}\left(k_{0}\right)$.

Implicit in the budget constraint is the assumption that the household is the supplier of loanable funds (via the bank at the competitive interest rate, $r$ ) to help finance the firm's investment.

The first-order condition implies that

$$
\frac{\dot{c}}{c}=\frac{r-\rho}{\sigma} .
$$

\section{Equilibrium Condition}

In equilibrium, consumption equals output net of investment, namely $c=f(k)-\delta k-\dot{k}$, or, alternatively,

$$
\dot{k}=f(k)-\delta k-c .
$$




\section{Linking the Firm Value and the Consumer Utility}

Proposition: The value of the firm is linked to the welfare of the representative consumer:

$$
\begin{aligned}
V\left(k_{0}\right) & =c_{0}^{\sigma} \int_{0}^{\infty} e^{-\rho t} c^{1-\sigma} d t, \\
& =c_{0}^{\sigma}\left[(1-\sigma) U\left(k_{0}\right)+\frac{1}{\rho}\right] .
\end{aligned}
$$

Remark: The superscript $o$ is purposely omitted here because the relation still holds even in the presence of market distortions. The key equations for establishing the link are (2) and (3). The proof is given in Appendix II and a closed-form example is given in Appendix III. In general, the computation of the value of the firm requires a numerical procedure, which can be found in detail in Xie and Yuen (2002). The procedure has two steps. First, the policy function, $c^{o}(k)$, is computed in the method of Mulligan and Sala-i-Martin (1991). Then the policy function is used to solve, backwards, a differential equation for $V^{o}(k)$ from the steady state.

Equation (4) has an interesting and surprising implication, namely, when $\sigma \geq 1$, the value of the firm can be greater in an economy with market distortions than without. To illustrate, let us use $\tilde{x}$ to denote variable $x$ under market distortions. Suppose that market distortions induce a consumption profile, $\left\{\tilde{c}_{t}\right\}_{0}^{\infty}$, that is flatter than the socially optimal one, $\left\{c_{t}^{o}\right\}_{0}^{\infty}$. In other words, $\tilde{c}_{0}>c_{0}^{o}$, but the rate of growth is lower under market distortions. Since social optimality implies that $U^{o}\left(k_{0}\right)>\tilde{U}\left(k_{0}\right)$, equation (4) clearly shows that $\tilde{V}\left(k_{0}\right)>V^{o}\left(k_{0}\right)$ when $\sigma \geq 1$.

So what is the intuition behind the possibility of higher firm value despite the fact that social welfare is necessarily lower in the presence of market distortions?

Note that the value of the firm is the present value of the consumption stream; hence, it depends on the real interest rates. Equation (2) can be rewritten as

$$
r=\rho+\sigma g_{c},
$$

where $g_{c}$ is the rate of growth of consumption. Therefore, whenever market distortions lower consumption growth, they will also lower real interest rates. The greater the value of $\sigma$ (namely a lower elasticity of intertemporal substitution), the larger the decline in the real interest rate in order to be consistent with the lower consumption growth. This large decline in the real interest rate could raise the present value of the firm under market distortions above its level under the social optimum.

One example of such market distortions would be a combination of an output tax and a lump-sum subsidy. In this paper, we focus on another type of distortion, namely, the presence of an investment-financing constraint.

\section{Investment-Financing Constraint}

We now examine a case in which the representative firm's investment is limited by its ability to obtain financing. We assume that there is an implicit, competitive banking sector that provides loans (at the real interest rate $r_{t}$ ) to finance the 
firm's investment no more than some fraction of its net present value, namely, $\dot{k}+\delta k_{t} \leq \gamma V\left(k_{t}\right)$ for any $t$.

There could be many reasons why the firm might not be able to borrow an amount greater than a fraction of its fundamental value; in particular, capital market imperfections such as default possibilities and asymmetric information problems (see Bernanke, Gertler, and Gilchrist, 1999.) This financing constraint can be viewed as a reduced-form representation of these imperfections that we do not explicitly model in this paper.

In the presence of the financing constraint, the firm's problem becomes

$$
\begin{array}{ll}
W\left(k_{0}\right)=\max \int_{0}^{\infty} e^{-\int_{0}^{t} r_{s} d s}[f(k)-\delta k-z] d t \\
\text { subject to: } \quad \dot{k}=z, \\
\\
\delta k+z \leq \gamma V(k) \\
k_{0} \text { given, }
\end{array}
$$

and $W \equiv V$. This problem can be solved as follows. Given any continuous and almost everywhere differentiable function $V$, the maximization problem is well defined and a function $W$ can be obtained. We can write $W=T(V)$, where $T$ is a mapping. Our task is to find the fixed point of $T$.

A rigorous investigation of the problem is the subject of an entirely different paper. For instance, to prove the existence of a fixed point, we would need to show that $T$ is a contraction mapping. Modification of the standard argument in dynamic programming would be required, but what is essential in the proof of contraction mapping is the presence of discounting in the objective function: $\rho>0$ in a continuous time model and $0<\beta<1$ in a discrete time model. Instead, we approach the problem in an intuitive fashion. First, we use the special case of $f(k)=A k^{\alpha}$ with $0<\alpha=\sigma<1$ to derive a special feature of the fixed point. Then we construct a value function $V$ displaying the same feature in more general cases when $f(k)=A k^{\alpha}$, where $\alpha \neq \sigma$.

To begin, note that in the absence of the financing constraint, explicit functional forms of the investment function $I^{o}(k)$ and the firm's value function $V^{o}(k)$ are available when $\alpha=\sigma$. We can see that $I^{o}(k)$ is hump-shaped, starting with $I^{o}(0)=0$, increasing and reaching a maximum, then declining and approaching negative infinity as $k$ goes to infinity. $V^{o}(k)$ is an increasing function starting with $V^{o}(0)=0$ and approaching infinity as $k$ goes to infinity. Furthermore, we have,

$$
\begin{aligned}
I^{o}(k)-\gamma V^{o}(k) & =\left[A k^{\alpha}-\frac{\rho+(1-\sigma) \delta}{\sigma} k\right]-\gamma\left[k+\left(\frac{1-\sigma}{\rho}\right) A k^{\alpha}\right] \\
& =\left[1-\gamma\left(\frac{1-\sigma}{\rho}\right)\right] A k^{\alpha}-\left[\gamma+\frac{\rho+(1-\sigma) \delta}{\sigma}\right] k .
\end{aligned}
$$

Clearly, if $\gamma$ is large, namely $\gamma \geq \rho /(1-\sigma)$, then $I^{o}(k)-\gamma V^{o}(k) \leq 0$ for any $k$; hence the financing constraint will never be binding. Let us focus on small $\gamma$ instead: $\gamma<\rho /(1-\sigma)$. With a small $\gamma$, we see that there exists a critical capital stock, $k^{c}$, 


$$
k^{c}=\left\{\frac{\left[1-\frac{\gamma(1-\sigma)}{\rho}\right] A}{\gamma+\frac{\rho+(1-\sigma) \delta}{\sigma}}\right\}^{1 /(1-\sigma)}>0
$$

such that $I^{o}\left(k^{c}\right)-\gamma V^{o}\left(k^{c}\right)=0$ and the financing constraint is only binding when $k<k^{c}$.

The existence of a critical $k^{c}$ is also true in more general cases when $f(k)=A k^{\alpha}$, where $\alpha \neq \sigma$. A proof is given in Appendix IV where such a fixed point, $V$, for the mapping $T$ is constructed. We now turn to a numerical example.

\section{A Numerical Example}

In our numerical example, we assume the following benchmark parameter values: $\alpha=0.36, \sigma=0.5, \gamma=0.015, \delta=0.1, A=12$, and $k_{0}=20$. We first compute the consumption function, the value function, and the investment function, $c^{o}(k), V^{o}(k)$, and $I^{o}(k)$, respectively, in the absence of the financing constraint by shooting backward from $k^{*}$ to $k_{0}$. Then we use $I^{o}(k)=\gamma V^{o}(k)$ to solve for the critical value $k^{c}$. The corresponding functions $c(k), V(k)$, and $I(k)$ in the presence of the investment-financing constraint can be obtained by shooting backward from $k^{c}$ to $k_{0}$ for $k \in\left[k_{0}, k^{c}\right]$ (when the constraint is binding) and combining it with $c^{o}(k), V^{o}(k)$, and $I^{o}(k)$ (when the constraint is nonbinding). The graphs for $\gamma V(k)$ with and without the financing constraint as well as the investment function $I^{o}(k)$ are displayed in Figure 1.

Not surprisingly, investment under the financing constraint is forced to be lower than $I^{o}(k)$ when $k<k^{c}$. Since contemporaneous output is unaffected by changes in investment, $c(k)>c^{o}(k)$ for $k<k^{c}$ (see Figure 2, panel 2). Also note that even when $\sigma=0.5$, we still find $V(k)>V^{o}(k)$ for $k<k^{c}$. This example shows that when the consumption profile is flatter under market distortions than under the social optimum, the condition $\sigma \geq 1$ is sufficient for $V(k)>V^{o}(k)$ but it is not necessary.

Given these functions, $c(k), V(k)$, and $I(k)$, we are ready to compute the time path of consumption (Figure 2, panel 1). We see that while consumption under the financing constraint initially exceeds its unconstrained counterpart, it grows at a slower rate and is soon surpassed by the latter. ${ }^{2}$

Given the consumption path, the real interest rate can be computed using equation (2), which holds with and without the financing constraint. As shown in Figure 3, panel 2, initially the interest rate is significantly lower with the investment constraint than without it. The constraint induces a jump in the interest rate from 4 percent to 5 percent at the time when the capital stock hits its critical value and gradually converges to its steady-state value of 3 percent thereafter.

The interest rate behavior under the financing constraint may suggest a partial resolution to the Lucas (1990) puzzle: why capital does not flow from rich to poor

\footnotetext{
${ }^{2}$ Observe that while the "constrained" consumption function lies everywhere above its "unconstrained" counterpart, the same is not true for the consumption paths. This is because capital (of which consumption is a function) will grow more slowly with the constraint than without it. The same logic applies to comparisons between policy functions of other variables and their corresponding time paths.
} 
Figure 1. Investment Function and Financing Constraint

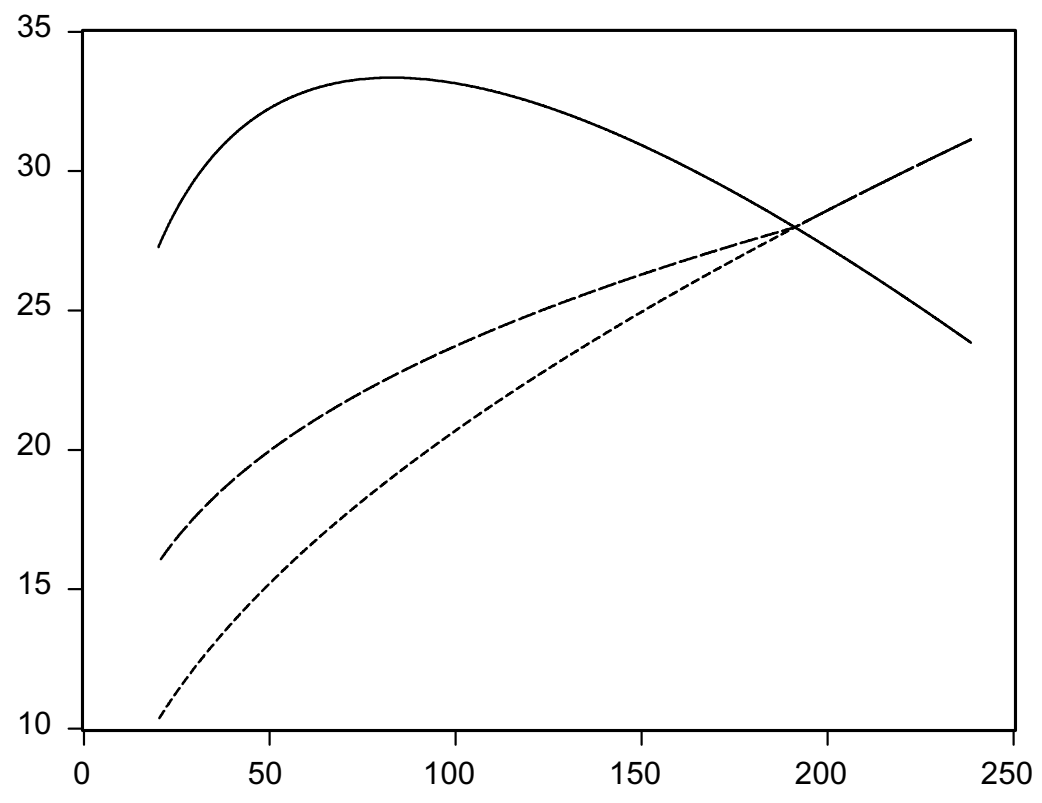

Capital Stock

- Investment function

Firm value multiplied by gamma (without financing constraint)

---- Firm value multiplied by gamma (with financing constraint)

countries. In particular, the interest rate functions as portrayed in Figure 4 indicate that while a 10-fold difference in capital stocks between rich and poor countries (say, $k=20$ versus $k=200$ ) could induce a more than 13-fold difference in their interest rates $(r(20)=0.535$ versus $r(200)=0.0455)$ in the absence of the constraint, the interest rate gap will be significantly reduced to 4-fold $(r(20)=0.188$ versus $r(200)=0.0455)$ under the constraint. It may sound tautological that the presence of a financing constraint reduces the interest rate differential across countries. In fact, the statement could be given an empirical content if one could calibrate the parameter $\gamma$ to obtain a quantitative measure of the reduction in interest rate differential. The remaining differential could then be attributed to other factors such as political risk and institutional and trade barriers.

\section{Discussion and Possible Extensions}

Our simple model can be easily extended to include labor as an additional input in the firm's production technology and the labor-leisure choice in the consumer's utility maximization problem. This extension would allow us to examine the effect of the financing constraint on employment as well—especially when the constraint 
Figure 2. Consumption Paths and Functions

Consumption Paths

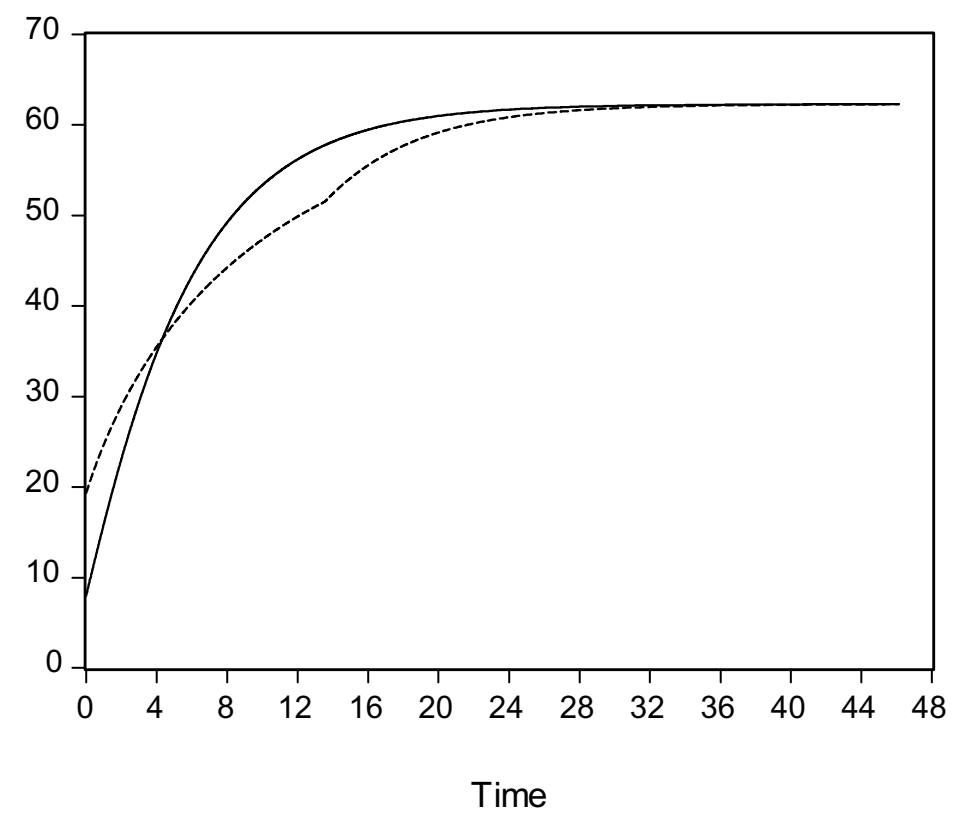

Consumption Functions

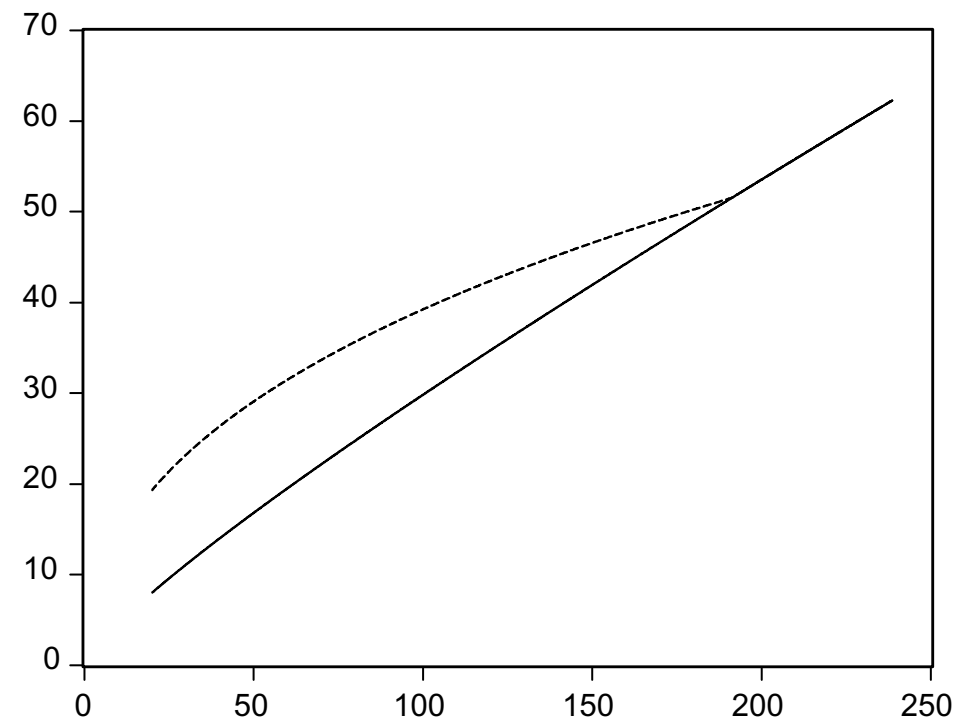

Capital Stock 
Figure 3. Capital and Real Interest Rate Paths

Capital Paths

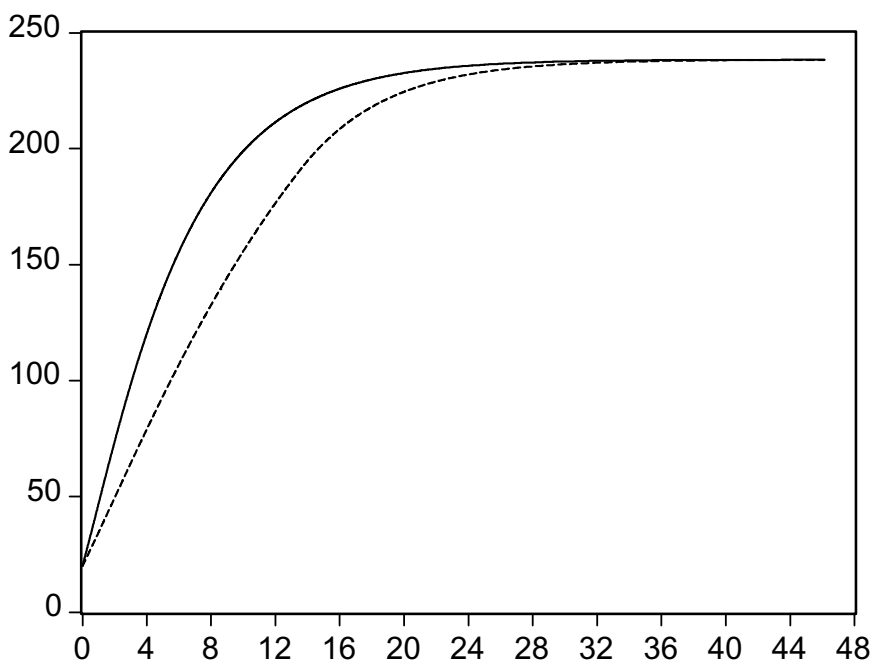

Time

- Capital path (without financing constraint) Capital path (with financing constraint)

Real Interest Rate Paths

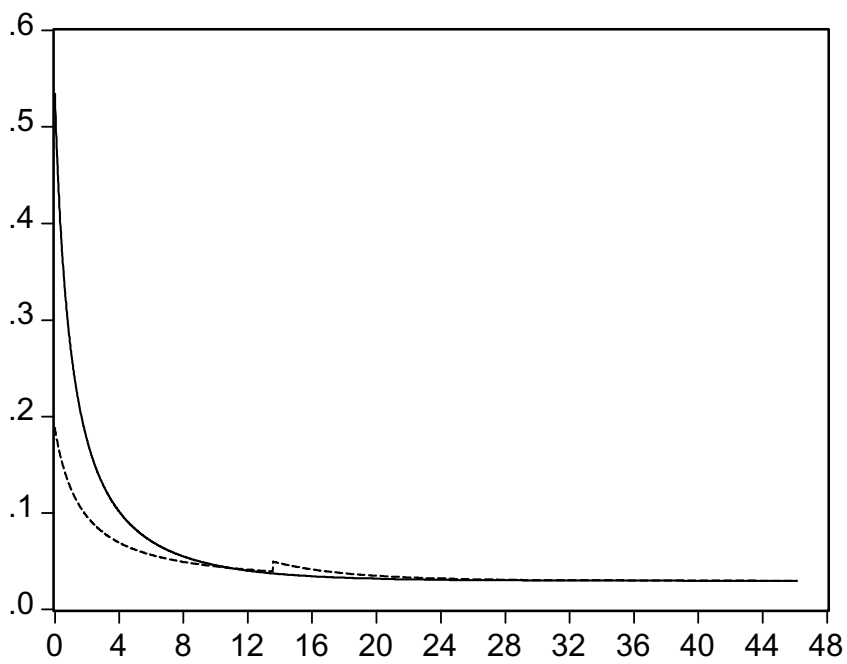

Time

- Interest rate (without financing constraint) Interest rate (with financing constraint) 
Figure 4. Interest Rate Functions

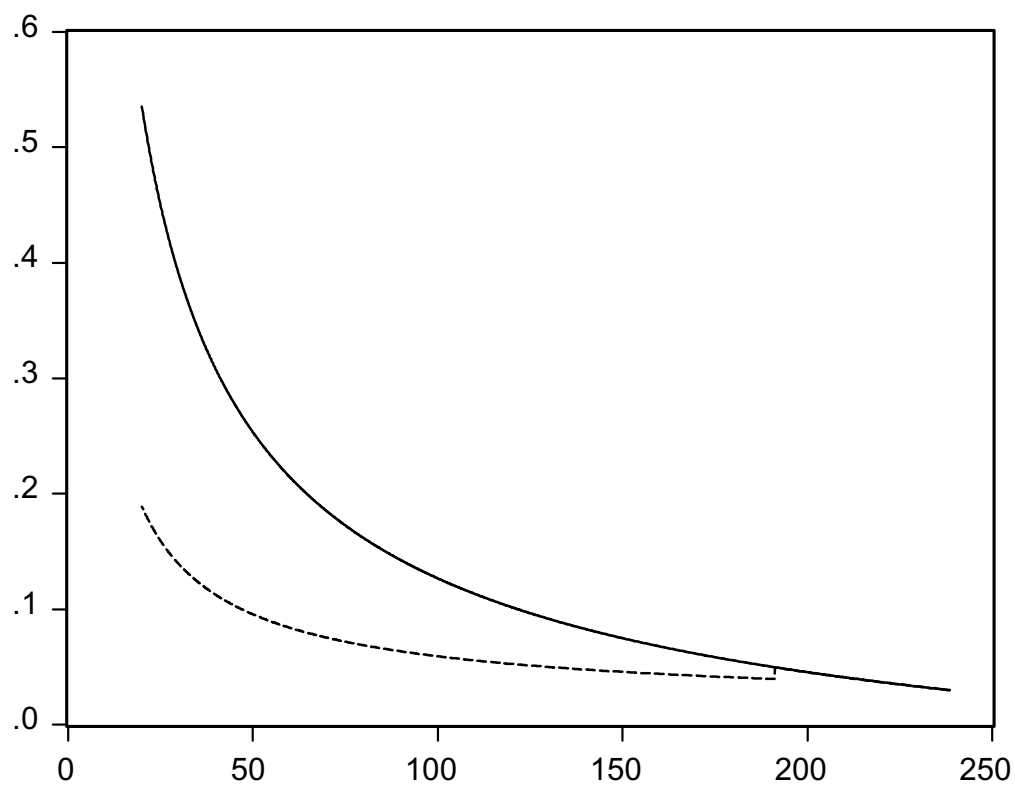

Capital Stock

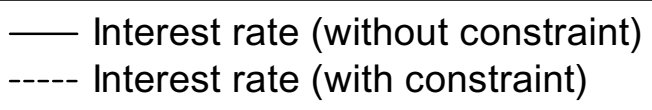

does not apply just to investment financing, but also to hiring workers and footing their wage bills. In the presence of this more severe constraint, employment and output could both be adversely affected so that consumption might not surge at the beginning despite the fall in investment.

This model is cast in a deterministic framework. The following discussion about its potential applications to cases with uncertainty is thus only suggestive.

- An increase in total productivity, $A$, will shift both the $\gamma V(k)$ and $I(k)$ schedules upward. The impact on investment is not a monotonic function of the capital stock. As shown in Figure 5 based on our numerical computations, the impact on investment is hump-shaped. This suggests that in emerging market economies, broadly interpreted as countries with capital somewhere between that of the lessdeveloped and the developed countries, investment is more responsive to productivity shocks than in the rest of the world.

- In a deterministic framework, it is easy to detect any discrepancy between $V$, the investors' perception of a firm's net worth, and $W$, the net worth based on fundamentals. In a stochastic world, there will always be a discrepancy between the two. Misperception can last for some time despite incoming data when capital stock is in a region where the investment constraint is binding. For example, when an important innovation such as the Internet raises total productivity (captured by parameter $A$ in our model), no one knows exactly the new value of $A$. 
Figure 5. Change in Productivity

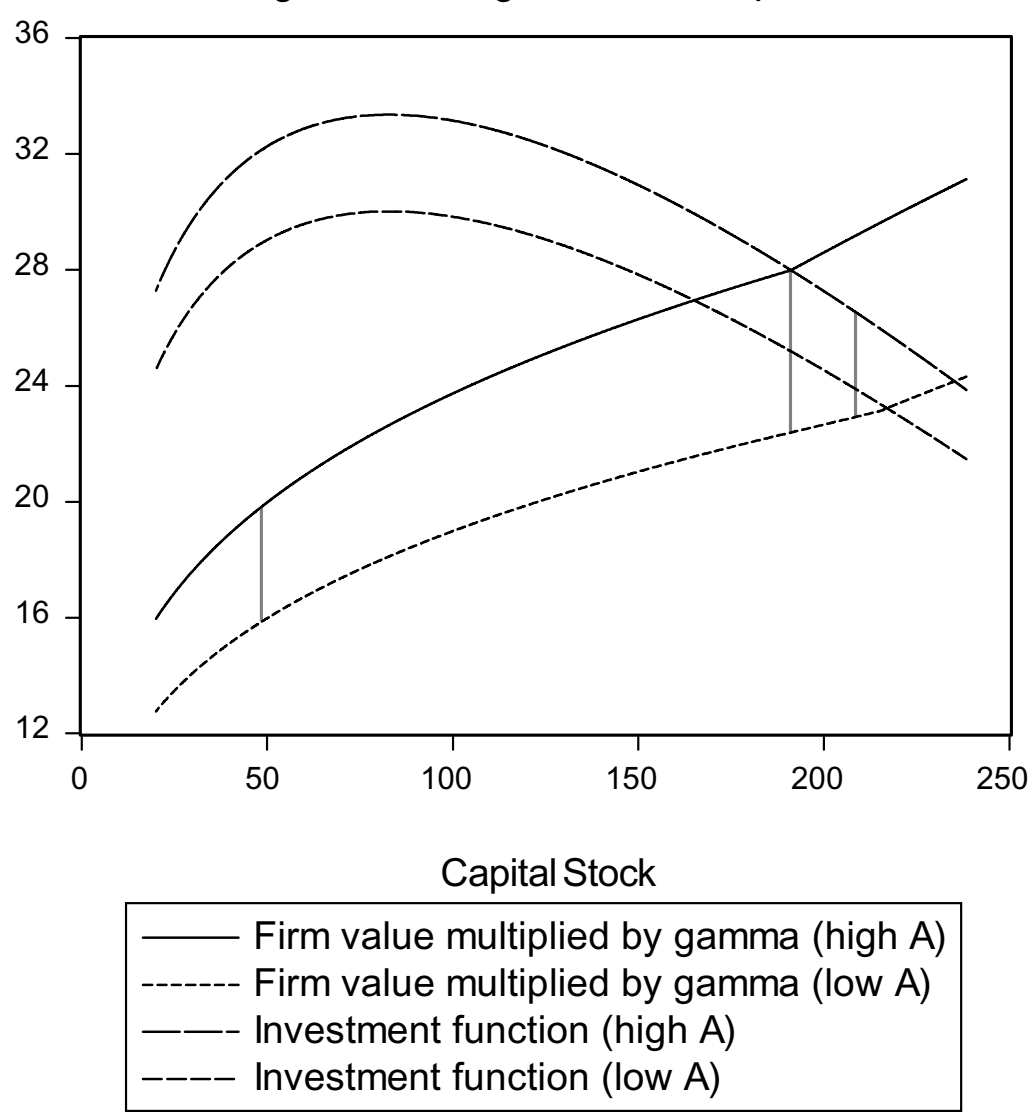

If the market estimate, $A_{M}$, is higher than the true $A$, the increased valuation of the firm's net worth will relax the financing constraint and allow the firm to raise its investment above the equilibrium level. As a result, output will be higher, which partially justifies the rise in market estimate $A_{M}$. Because it may take some time for the investors to gauge the real impact of the innovation and because the calculation of the fundamental value $W$ involves projection of future profits, the discrepancy between $W$ and $V$ may not be statistically detectable for a number of years. Only when subsequent earnings reports of the firm consistently reveal that $V$ is significantly above $W$ would $A_{M}$ be revised downward. Again, no one knows precisely how much downward revision is warranted for $A_{M}$. Doubtless in wellfunctioning markets, investors' profit incentive would lead $A_{M}$ to settle around the true $A$ in the long run; but in the short run, overshooting can occur on either the upside or downside whenever an important innovation in general-purpose technology comes on the scene. The magnitude of investment fluctuations depends on the level of the capital stock. Figure 6 indicates investment would be more volatile in emerging market economies than in the rest of the world. To be sure, a logically consistent model of business cycles would require an explicit probability specification of the magnitude and the dynamics of misperception. 
Figure 6. Misperception: Optimism and Pessimism

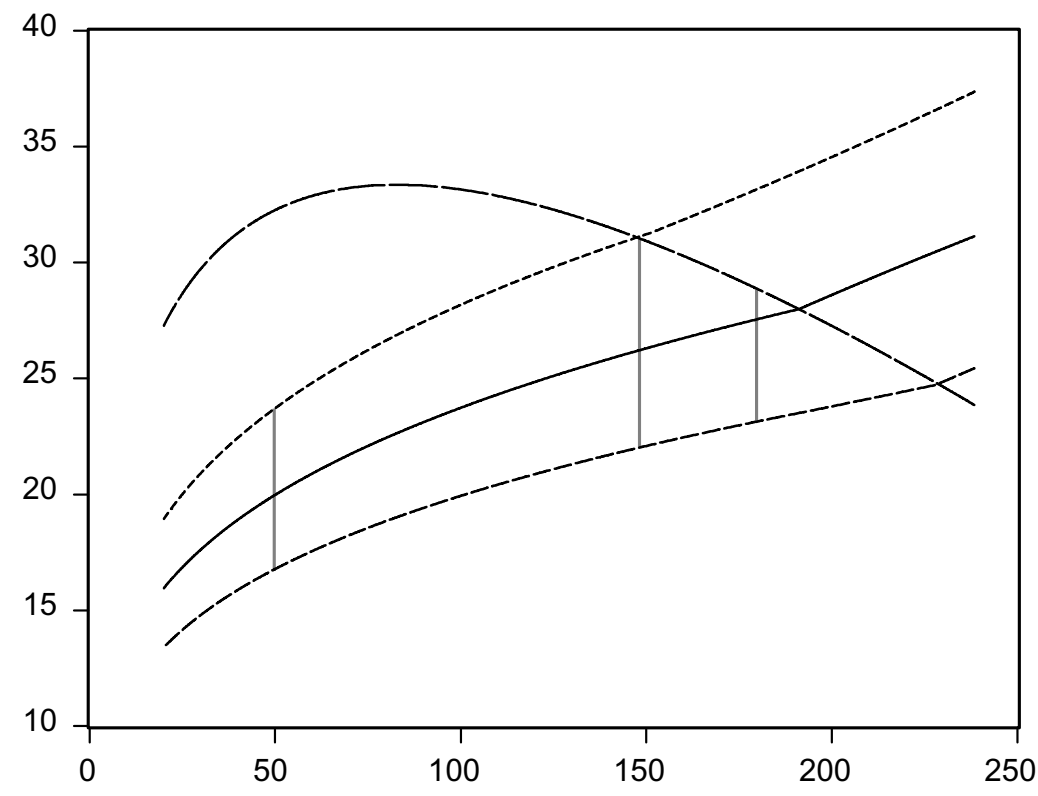

Capital Stock

- Firm value multiplied by gamma
------ Optimism
---- Pessimism
-- Investment function

- The recent accounting scandals in the United States, such as those involving the Enron Corp. and WorldCom Inc., would lower the value of $\gamma$, resulting in tighter financing constraint and hence lower aggregate investment. The congressional effort to tighten government regulations by raising accounting standards and making CEOs more accountable to shareholders will likely stop $\gamma$ from sliding further and thus should stabilize investment. In a fullfledged real business cycle (RBC) model with investment constraint, the parameter $\gamma$ should be calibrated to changes in government regulation and supervision in financial markets. For instance, China's increasing effort since 1996 to adapt its financial markets to international standards in preparation for its accession to the World Trade Organization will allow banks to raise $\gamma$ in their decision to provide loans to the private sector, thereby raising private investment. Even in the absence of technical progress, therefore, institutional changes that ease the problem of asymmetric information in the financing process would mean a higher $\gamma$ and a less stringent financing constraint. As a result, capital can be accumulated more rapidly; and as the capital stock passes the financing threshold, the investment volatility discussed in the paragraph above will eventually become more moderate. 
- As implied by the discussion above, both technological progress and institutional improvement can raise investment and output. Traditional RBC models do not distinguish one change from the other. Accounting separately for the change in $A$ and the change in $\gamma$ requires serious effort in gathering and examining relevant empirical data - such as the trust indicator reported in Knack and Keefer (1997) and the survey data on bank regulation and supervision in Barth, Caprio, and Levine (2001). For a developing country trapped in low investment, the priority for policy changes is likely to be different, depending on whether the low investment is caused by a low $A$, in which case importing advanced technologies and ideas would help, or a low $\gamma$, in which case rules and regulations improving the transparency of business transactions are called for. In the sense of Prescott (1986), here again, "theory is ahead of business cycle measurement."

A more rigorous analysis of these issues is left for future research.

\section{APPENDIX I}

\section{A More Detailed Description of the Banking Sector in Discrete Time}

At time zero, the household uses its initial capital, $k_{0}$, to purchase shares of the firm and thus becomes its owner. With $k_{0}$, the firm produces $f\left(k_{0}\right)$, which it pays to the household as dividends. It then borrows $I_{0}$ from the bank at the competitive interest rate $r_{0}$ to finance its investment. When time 1 comes around, the capital stock grows to $k_{1}=I_{0}+(1-\delta) k_{0}$, yielding output $f\left(k_{1}\right)$. After repaying principal and interest to the bank, the residual $f\left(k_{1}\right)-I_{0}\left(1+r_{0}\right)$ is paid out to the household. A new loan is then secured to finance investment $I_{1}$ at interest rate $r_{1}$. At time 2 the capital stock $k_{2}=I_{1}+(1-\delta) k_{1}$ generates output $f\left(k_{2}\right)$ and dividend $f\left(k_{2}\right)-I_{1}\left(1+r_{1}\right)$. And so on and so forth.

Therefore, the value of the firm equals the present value of the net cash flow, i.e.,

$$
\begin{aligned}
V\left(k_{0}\right) & =f\left(k_{0}\right)+\left(\frac{1}{1+r_{0}}\right)\left[f\left(k_{1}\right)-I_{0}\left(1+r_{0}\right)\right]+\left(\frac{1}{1+r_{0}}\right)\left(\frac{1}{1+r_{1}}\right)\left[f\left(k_{2}\right)-I_{1}\left(1+r_{1}\right)\right]+\ldots \\
& =\left[f\left(k_{0}\right)-I_{0}\right]+\left(\frac{1}{1+r_{0}}\right)\left[f\left(k_{1}\right)-I_{1}\right]+\left(\frac{1}{1+r_{0}}\right)\left(\frac{1}{1+r_{1}}\right)\left[f\left(k_{2}\right)-I_{2}\right]+\ldots
\end{aligned}
$$

The household receives $f\left(k_{t}\right)-I_{t-1}\left(1+r_{t-1}\right)$ from the firm as its shareholder and $I_{t-1}\left(1+r_{t-1}\right)$ from the firm as its debt holder, consumes $c_{t}=f\left(k_{t}\right)-S_{t}$, and deposits its savings, $S_{t}$, with the bank. In equilibrium, supply of loans by the household, $S_{t}$, equals demand for loans by the firm, $I_{t}$, so that $c_{t}=f\left(k_{t}\right)-I_{t}$ and the present value of consumption simply equals the firm's value.

\section{APPENDIX II \\ Proof of Proposition}

Substituting $\dot{k}$ from (3) and $r_{s}$ from (2) into the firm's value function, we have,

$$
V\left(k_{0}\right)=c_{0}^{\sigma} \int_{0}^{\infty} e^{-\rho t} c^{1-\sigma} d t,
$$

which immediately gives,

$$
V\left(k_{0}\right)=c_{0}^{\sigma}\left[(1-\sigma) U\left(k_{0}\right)+\frac{1}{\rho}\right] .
$$




\section{APPENDIX III}

\section{A Closed-Form Example}

In the particular case when $f(k)=A k^{\sigma}$ we have $c(k)=[\rho+(1-\sigma) \delta] k / \sigma$ (see Xie, 1991). Therefore,

$$
\begin{aligned}
U\left(k_{0}\right) & =\frac{1}{1-\sigma} \int_{0}^{\infty} e^{-\rho t} c^{1-\sigma} d t-\frac{1}{(1-\sigma) \rho} \\
& =\frac{1}{1-\sigma}\left[\frac{\rho+(1-\sigma) \delta}{\sigma}\right]^{1-\sigma} \int_{0}^{\infty} e^{-\rho t} k^{1-\sigma} d t-\frac{1}{(1-\sigma) \rho},
\end{aligned}
$$

where, with $\dot{k}=\left[\sigma A k^{\sigma}-(\rho+\delta) k\right] / \sigma$, we have:

$$
\begin{aligned}
\int_{0}^{\infty} e^{-\rho t} k^{1-\sigma} d t & =-\left.\frac{e^{-\rho t}}{\rho} k^{1-\sigma}\right|_{0} ^{\infty}+\int_{0}^{\infty} \frac{e^{-\rho t}}{\rho}(1-\sigma) k^{-\sigma} \dot{k} d t \\
& =\frac{1}{\rho} k_{0}^{1-\sigma}+\int_{0}^{\infty} \frac{e^{-\rho t}}{\rho}(1-\sigma)\left[\frac{\sigma A-(\rho+\delta) k^{1-\sigma}}{\sigma}\right] d t \\
& =\frac{1}{\rho} k_{0}^{1-\sigma}+\frac{(1-\sigma) A}{\rho^{2}}-\frac{(1-\sigma)(\rho+\delta)}{\rho \sigma} \int_{0}^{\infty} e^{-\rho t} k^{1-\sigma} d t
\end{aligned}
$$

Hence,

$$
\int_{0}^{\infty} e^{-\rho t} k^{1-\sigma} d t=\frac{k_{0}^{1-\sigma}+\left(\frac{1-\sigma}{\rho}\right) A}{\frac{\rho+(1-\sigma) \delta}{\sigma}},
$$

implying

$$
U\left(k_{0}\right)=\left(\frac{1}{1-\sigma}\right)\left\{\frac{k_{0}^{1-\sigma}+\left(\frac{1-\sigma}{\rho}\right) A}{\left[\frac{\rho+(1-\sigma) \delta}{\sigma}\right]^{\sigma}}-\frac{1}{\rho}\right\}
$$

and

$$
V\left(k_{0}\right)=k_{0}+\left(\frac{1-\sigma}{\rho}\right) A k_{0}^{\sigma} .
$$

\section{APPENDIX IV \\ Construction of a Fixed Point}

For any given $V(k)$, the first-order conditions in the firm's problem are given by

$$
e^{-\int_{0}^{t} r_{s} d s}=\lambda-\theta
$$

and

$$
\dot{\lambda}=-e^{-\int_{0}^{t} r_{s} d s}\left(\alpha A k^{\alpha-1}-\delta\right)-\theta\left[\gamma V^{\prime}(k)-\delta\right],
$$

where $\lambda$ and $\theta$ are the multipliers associated with $\dot{k}=z$ and the financing constraint, respectively, and $\theta$ satisfies the following complementary slackness condition:

$$
\theta[\gamma V(k)-\delta k-\dot{k}]=0 \text {. }
$$


The consumer's problem remains the same as before. Therefore, equation (2) still holds and equation (4) holds with $W$ in place of $V$ :

$$
W\left(k_{\tau}\right)=c_{\tau}^{\sigma} \int_{\tau}^{\infty} e^{-\rho(t-\tau)} c_{t}^{1-\sigma} d t
$$

Differentiating (7) with respect to $\tau$ yields,

$$
W^{\prime}(k) \dot{k}=r W(k)-c(k) \text {. }
$$

When $k \geq k^{c}$ the financing constraint is not binding, so $\theta=0$ and the policy and value functions are the same as in the unconstrained case described in Xie and Yuen (2002), with $c(k)=c^{o}(k)$, $W(k)=V(k)=V^{o}(k)$, etc.

In what follows, we shall focus on the case where the constraint is binding, i.e., $k<k^{c}$ and $\theta>0$. Is there a differential equation that governs $c(k)$ ? From equation (3) and the binding constraint, we have

$$
A k^{\alpha}-c(k)=\gamma V(k) \text {. }
$$

Differentiate this with respect to $t$. Making use of equations (2) and (8) and imposing $V \equiv W$, we obtain

$$
\left[\alpha A k^{\alpha-1}-c^{\prime}(k)\right] \dot{k}=\left[\rho+\sigma \frac{c^{\prime}(k)}{c(k)} \dot{k}\right]\left[A k^{\alpha}-c(k)\right]-\gamma c(k),
$$

which implies that

$$
c^{\prime}(k)=\frac{\alpha A k^{\alpha-1} c(k)}{\left[(1-\sigma) c(k)+\sigma A k^{\alpha}\right]}+\frac{(\gamma+\rho) c^{2}(k)-\rho c(k) A k^{\alpha}}{\left[(1-\sigma) c(k)+\sigma A k^{\alpha}\right]\left[A k^{\alpha}-\delta k-c(k)\right]} .
$$

We can compute $c(k)$ by working backward from $k^{c}$ and $c\left(k^{c}\right)=c^{o}\left(k^{c}\right)$.

Once $c(k)$ is computed, $V(k)$ can be found from the financing constraint simply as

$$
V(k)=\left[A k^{\alpha}-c(k)\right] / \gamma .
$$

The fact that we make use of equation (8) and impose $W \equiv V$ in our derivation of $c^{\prime}(k)$ above ensures that this $V(k)$ is the fixed point of the mapping $T$. Hence the function $V$ that we construct here is the value function of the firm. 


\section{REFERENCES}

Barth, James R., Gerard Caprio, Jr., and Ross Levine, 2001, "Bank Regulation and Supervision: What Works Best?" Working Paper No. 2725 (Washington: World Bank).

Bernanke, Ben S., Mark Gertler, and Simon Gilchrist, 1999, "The Financial Accelerator in a Quantitative Business Cycle Framework," in Handbook of Macroeconomics, Vol. 1, ed. by John B. Taylor and Michael Woodford (Amsterdam: North-Holland).

Carlstrom, Charles, and Timothy Fuerst, 1997, "Agency Cost, Net Worth, and Business Fluctuations: A Computable General Equilibrium Analysis," American Economic Review, Vol. 87, pp. 893-910.

Chakraborty, Shankha, and Tridip Ray, 2001, "Bank-Based versus Market-Based Financial Systems: A Growth-Theoretic Analysis,” Working Paper No. EC01-08 (Hong Kong: Hong Kong University of Science and Technology).

Chami, Ralph, and Thomas F. Cosimano, 2001, "Monetary Policy with a Touch of Basel," IMF Working Paper 01/151 (Washington: International Monetary Fund).

Chang, Roberto, and Andrés Velasco, 2000, "Financial Fragility and Exchange Rate Regimes," Journal of Economic Theory, Vol. 92, pp. 1-34.

Chen, Nan-Kuang, 2001, "Bank Net Worth, Asset Prices and Economic Activity," Journal of Monetary Economics, Vol. 48, No. 2, pp. 415-36.

Kashyap, Anil K., and Jeremy C. Stein, 1995, "The Impact of Monetary Policy on Bank Balance Sheets," Carnegie-Rochester Conference Series on Public Policy, Vol. 42, pp. 151-95.

Kiyotaki, Nobuhiro, and John Moore, 1997, "Credit Cycles," Journal of Political Economy, Vol. 105, pp. 211-48.

Knack S., and P. Keefer, 1997, "Does Social Capital Have a Payoff? A Cross Country Investigation," Quarterly Journal of Economics, Vol. 112, pp. 1251-88.

Krugman, Paul, 2002, "Crises: The Next Generation," in Economic Policy in the International Economy: Essays in Honor of Assaf Razin, ed. by Elhanan Helpman and Efraim Sadka (Cambridge: Cambridge University Press).

_ , 1999, "Balance Sheet Effects, the Transfer Problem, and Financial Crises," International Tax and Public Finance, Vol. 6, No. 4, pp. 459-72.

— 1998, "Bubble, Boom, Crash: Theoretical Notes on Asia's Crisis" (unpublished; Cambridge, Massachusetts: Massachusetts Institute of Technology).

— 1979, "A Model of Balance-of-Payment Crises," Journal of Money, Credit, and Banking, Vol. 11, pp. 311-25.

Lucas, Robert E., Jr., 1990, "Why Doesn't Capital Flow From Rich to Poor Countries?" American Economic Review, Papers and Proceedings, Vol. 80, pp. 92-96.

Mulligan, Casey, and Xavier Sala-i-Martin, 1991, "A Note on the Time-Elimination Method for Solving Recursive Dynamic Economic Models," NBER Technical Paper No. 116 (Cambridge, Massachusetts: National Bureau of Economic Research).

Obstfeld, Maurice, 1996, "Models of Currency Crises with Self-Fulfilling Features," European Economic Review, Vol. 40, No. 3-5, pp. 1037-48.

___ , and Kenneth Rogoff, 1996, Foundations of International Macroeconomics (Cambridge, Massachusetts: MIT Press).

Prescott, Edward, 1986, "Theory Ahead of Business-Cycle Measurement," Carnegie-Rochester Conference Series on Public Policy, Vol. 25, pp. 11-44. 
Schneider, Martin, and Aaron Tornell, 2000, "Balance Sheet Effects, Bailout Guarantees, and Financial Crises," NBER Working Paper No. 8060 (Cambridge, Massachusetts: National Bureau of Economic Research).

Van den Heuvel, Skander J., 2001, "The Bank Capital Channel of Monetary Policy” (unpublished; Philadelphia: University of Pennsylvania).

Xie, Danyang, 1991, "Increasing Returns and Increasing Rates of Growth," The Journal of Political Economy, Vol. 99, No. 2, pp. 429-35.

— with Financing Constraint," IMF Working Paper 02/41 (Washington: International Monetary Fund). 